\title{
The Influence of Native Language on Ghanaian Junior Secondary School Students' Understanding of some Science Concepts
}

\author{
Ngman-Wara, E. \\ Dept. of Science Education, University of Education, Winneba, Ghana
}

\section{Abstract}

\begin{abstract}
The purpose of the study was to investigate the effect of the native language of Junior Secondary School (JSS) students on the meanings they give to science words when used in and out of science context. Two multiple choice tests involving twenty-five common words in science were administered to 1028 students (573 males and 455 females) from twelve Junior Secondary Schools (6 urban and 6 rural) in Northern Ghana. The tests first sought to find out the extent to which the students' understand the science concepts and secondly to find out how their native language influenced this understanding. The general performance of the students was very low. They performed better on 'science concepts with native language equivalent words' than those without 'native language equivalent words' with percentage mean scores of $32.2 \%$ and $29.1 \%$ respectively. In this light, the paper argues that the native language of the learner has an influence on the students' understanding of science concepts and that the native language of the student can not be ignored during science instruction. There is therefore the need to develop language register for science instruction.
\end{abstract}

\section{Introduction}

Language is one of the various media through which every culture expresses its concepts about the environment. It is a vehicle for the expressions of thoughts from which the concepts concerning the environment are formed by the individual. In science teaching, these functions of language can only be effective if common meanings are given to the words encountered during the teaching/learning process and in scientific texts. This situation can be facilitated if the language of instruction is the first language of the learner (Mori et. al., 1976) and the words used are understood in the context in which they are used (Bently and Watts, 1992).

Learning science through a second language may pose a number of problems. Every culture has its unique language through which the individual's perceptions of the world are expressed (Alexander, 1967). Therefore words used during instruction in science may have different cultural roots from those of the native language of the learner. In science education, certain words needed to explain certain natural phenomena or to understand some science concepts may or may not be available when a foreign language is the medium of instruction. For example, a study conducted by Yakubu (1976) to identify equivalent words in Kusaal language for such concepts as: temperature, energy and speed in parts of Northern Ghana showed that they were non existent.

Among the Kpelle of Liberia, Gay and Cole (1967) found that though they measured time and volume, their culture lacked measurements of weight, area and time. The learning of these words without local equivalents proved difficult for the students. In another study carried out by Mori and Kitagawa (1974) to find out the role of native language on children's formation of the concept of speed by Japanese and Thai children, it was found that the Thai language accelerated the Thai children's acquisition of the concept of speed while the Japanese language impeded the Japanese children's development of the concept. Therefore the native language of the child can facilitate or hinder the child's understanding of science (concept) words. Collison (1974) carried out a study to compare the native language and English language as medium of instruction for concept acquisition among Ghanaian children. The study 
revealed consistently that where English was the language of instruction, majority of the experimental subjects were not able to exercise their conceptual potential. The native languages proved more fruitful for enhancing the class interaction of the children.

Tobin and Mcrobbie (1996) investigated the significance of limited English proficiency (LEP) to performance in science of Chinese-Australian students. The investigation revealed that despite the students' effort to learn chemistry, difficulties in speaking and writing English were factors that limited their performance. The study also supported the assertion that learning chemistry could be facilitated when LEP students were provided with opportunities to fully employ their native language tools. Also Tobin and Crobbie (1996) showed that science achievement of limited English proficiency (LEP) students in grade 10 was statistically lower than that of students who were proficient in English in all the content areas assessed. Benz (1996) followed eleven non-English speaking students as they adapted to community college content courses taught in English. The non-English students were examined in three areas including requirement for content classes. The study revealed that the students drew on their native language education as they coped with the demands of the content classes. The native language is therefore an important factor which cannot be ignored in science concept formation.

Literacy plays an important role in determining school-aged children's academic achievement (Garcia, Ku and Reyes, 2001). The ability to read and write in one language may not be easily acquired for young users because it involves mastering skills that are specific to the written language. The task is even more challenging for second language learners. For students whose native language is not English, the process of literacy development in English can be particularly difficult if they did not bring to the learning process a foundation of literacy in their own language. The development of literacy in student's native language provides the social, cognitive, and linguistic foundation for academic success (Garcia, Ku and Reyes, 2001). It is through their first languages and home cultures, that students create frameworks for new understanding. Learning the language of science starts prior to formal education. Communication skills start before academic skills. Thus family communication appears to be of importance in developing the academic skills of the learner and the family's patterns can affect the development of a child's science literacy skills as well.

In Ghana, as a national policy, the native language is used as the medium of instruction during the first 3 years of primary schooling; thereafter, English language is used as the medium of instruction. The effect of this switch to English language, on the acquisition of science concepts has not been investigated at the JSS level. It is therefore desirable to study the meanings Ghanaian JSS students give to science concepts words when used out of and in science context and whether the native language of the student has any influence on the interpretation she/he gives to the words out of, and, in science context.

\section{Method}

\section{Sample}

The study involved 1028 students (573 male and 455 females) from 12 junior secondary schools ( 6 in rural areas: 247 males, 162 females; 6 in urban areas: 362 
males, 293 females) in Navrongo District of Upper East Region of Ghana. Whole classes of forms 1 to 3 were used. The average age of the students was 14 years. The principal native languages spoken in the area are Nakani, Buli, and Kassem. However Kassem is predominantly spoken and it is the official native language studied as a subject in the junior secondary schools.

In the rural areas agricultural activities are the predominant occupation of the adult population. Those in the urban areas are either government employees or small scale business men and women. Majority of the urban population is literate while the reverse is the case for the rural areas. The language environments of the schools investigated were different. Though the schools were poorly staffed, the rural schools were worse off than the urban schools. In most cases there were only three teachers handling all subjects in the school. Some of the schools had more than a class in a form. The contact hours between the English language teachers and the students were quite reduced because of the poor staffing of the schools. Moreover majority of the teachers handling the English language classes were teachers with Diploma certificate in Ghanaian Languages.

The highest qualification of the teachers was a Diploma certificate in Ghanaian Language. Majority of the teachers were 3-year post-Secondary Certificate 'A' Teachers. Those handling the science courses did general courses in Agricultural science or General Science. Some of the rural schools investigated had no qualified Science and English Language teachers. It was common to find untrained ordinary level holders and senior secondary school certificate holders teaching English language classes.

Despite the efforts by the Ghana Government to supply each basic school student at each level with a copy of the recommended English readers and a textbook for each other subject, the ratio was still two students to a reader and a textbook for each other subject. Also the students were not allowed free access to the books. They were allowed to use them only during English language lessons. This further decreased the contact hours between the students and the readers.

\section{Instrumentation}

The instrument used for the study consisted of two multiple choice tests (Test A and Test B) involving twenty-five science words. The words are encountered by the students in their daily use of English language, and are used in radio and television broadcasts. They are also found in the textbooks used at the three levels of the junior secondary school.

Test A, which was administered first, required the students to select from four options numbered A-D the word similar in meaning to the word being tested which was not used in any specific context. 


\section{E.g. Rate can mean}
A. Shape
B. Size
C. Speed
D. Distance

Test B, which was administered immediately after test A, involved the same words but each was used in specific science context. For each item, the subjects were also expected to choose from four options numbered A-D the one that best explained the word tested in the science context.

E.g. The experiment is designed to study the rate of evaporation. This means it is designed to study:
A. What happened during evaporation?
B. how quickly evaporation takes place
C. what is left after evaporation
D. why evaporation takes place

The content validity of the instrument was determined by four senior science educators in the University of Cape Coast. They individually confirmed the fact that the words as used in the instrument are among words in common usage in the science textbooks for JSS students in Ghana. Since the instrument was modified to suit the cultural context of the students of the study area, a pilot study was carried out to determine the reliability of the instrument. The KR-20 formula was used to establish the internal consistency of the instrument. The reliability coefficients were 0.85 and 0.80 for test $\mathrm{A}$ and $\mathrm{B}$ respectively, which were found adequate for the study. 


\section{Results and Discussion}

The frequency distribution of the students' scores on the interpretation of science words when used out of (test A) and in science context (test B) are presented in Table 1.

Table 1 JSS students' number and percentage of correct responses to test items.

\begin{tabular}{|c|c|c|c|c|}
\hline \multirow[b]{2}{*}{$\begin{array}{l}\text { Science concept } \\
\text { word tested }\end{array}$} & \multicolumn{2}{|c|}{$\begin{array}{l}\text { Correct Responses when used out of } \\
\text { science context (Test A) }\end{array}$} & \multicolumn{2}{|c|}{$\begin{array}{l}\text { Correct Responses when used in } \\
\text { science context (Test B) }\end{array}$} \\
\hline & $\begin{array}{l}\text { Number of } \\
\text { students } \\
(\mathrm{N}=\mathbf{1 0 2 8}) \\
\end{array}$ & $\begin{array}{l}\text { Percentage } \\
\text { correct Responses }\end{array}$ & $\begin{array}{l}\text { Number of } \\
\text { students } \\
(\mathrm{N}=\mathbf{1 0 2 8})\end{array}$ & $\begin{array}{l}\text { Percentage } \\
\text { correct Responses }\end{array}$ \\
\hline Average & 305 & 29.7 & 321 & 31.2 \\
\hline Disperse & 266 & 25.9 & 432 & 42.0 \\
\hline Displace & 422 & 41.1 & 339 & 33.0 \\
\hline Conserve & 372 & 36.2 & 368 & 35.8 \\
\hline Contaminate & 310 & 30.2 & 338 & 32.9 \\
\hline Effect & 171 & 16.6 & 265 & 25.8 \\
\hline Essential & 411 & 40.0 & 419 & 40.8 \\
\hline Estimate & 214 & 20.8 & 270 & 26.3 \\
\hline Convert & 256 & 24.9 & 293 & 28.5 \\
\hline Rate & 209 & 20.3 & 289 & 28.1 \\
\hline Source & 372 & 36.2 & 335 & 32.6 \\
\hline Prepare & 534 & 51.9 & 307 & 29.9 \\
\hline Separate & 485 & 47.2 & 366 & 35.6 \\
\hline Surround & 272 & 26.5 & 247 & 24.0 \\
\hline Dehydrated & 199 & 19.4 & 249 & 24.2 \\
\hline Function & 256 & 24.9 & 382 & 37.2 \\
\hline Proportion & 197 & 19.2 & 276 & 26.8 \\
\hline System & 353 & 34.3 & 399 & 38.8 \\
\hline Generate & 222 & 21.6 & 434 & 42.2 \\
\hline Device & 358 & 34.8 & 229 & 22.3 \\
\hline Crude & 230 & 22.4 & 402 & 39.1 \\
\hline Efficient & 186 & 18.1 & 380 & 37.0 \\
\hline Independent & 596 & 58.0 & 285 & 27.7 \\
\hline Absorb & 124 & 27.9 & 278 & 27.0 \\
\hline Constant & 205 & 19.9 & 219 & 21.3 \\
\hline
\end{tabular}

$\mathrm{N}$ is the total number of students who participated in the study

The performance of the students in both tests was generally very poor. Less than half of the students (1028) gave correct interpretations to the science words in both tests except the words "independent" and "prepare" in test A where $596(58 \%)$ and 534 $(51.9 \%)$ of the students gave correct interpretations to the words respectively (Table1). The mean scores of the tests (A and B) were 6.53 and 7.68 respectively. The students seemed to have performed better in test $B$. Despite the general poor performance on the tests, there was a significant difference $(\mathrm{t}=4.05, \mathrm{df}=1026, \mathrm{p}<$ 0.001 ) between the student mean scores in test $\mathrm{A}$ and $\mathrm{B}$. The students performed better in test $\mathrm{B}($ mean $=7.68)$ than in test $\mathrm{A}$ (mean $=6.53)$. The general trend was an increase in the frequency scores for corresponding test items in test B, except in few instances involving "displace", "conserve", "source", "prepare", "device" and "independent" (Table 1). The improvement in the test scores may be due to the context based nature of test B where the words were used in science context. The context might have made the meanings of the words clearer except those indicated above. 
The poor performance of the students in test A may be due to a number of factors such as poor vocabulary and word association, the general poor standard in English language among Ghanaian pupils at the basic school level (Sandman, 1993; Kraft, 1994). Poor vocabulary and poor word association may hinder science concept formation since literacy plays an important role in determining students' academic performance (Garcia, Ku and Reyes, 2001).

Some of the words have equivalent words in Kassem, the official native language of the students. Tables 2 and 3 show some of the words tested which native language equivalent words and words have tested without native language equivalent words respectively.

Table 2 Students' performance on concepts with native language equivalents

\begin{tabular}{lllc}
\hline & & \multicolumn{2}{c}{$\%$ Correct Interpretation } \\
\cline { 2 - 4 } Science Concept Tested & Native language equivalent of concept & Test A & Test B \\
Disperse & 'jage' (scatter) & 25.6 & 42.0 \\
Prepare & 'ke' (make) & 51.9 & 29.9 \\
Conserve & 'che/'gere' (save) & 36.2 & 35.8 \\
Surround & 'gelimi' (encircle) & 26.5 & 24.0 \\
Function & 'tonga' (work) & 24.9 & 37.2 \\
Convert & 'lere' (change) & 24.9 & 28.5 \\
Estimate & 'mange' (measure) & 20.8 & 26.3 \\
Displace & 'le' (remove) & 41.1 & 33.0 \\
Average & 'mange' (measure) & 29.7 & 31.2 \\
Separate & 'Iwe' (pick) & 47.2 & 35.6 \\
Absorb & 'ngu' (drink/soak) & 27.9 & 27.0 \\
& Average \% Correct & 32.4 & 31.9 \\
\hline
\end{tabular}

Table 3

Students' performance on concepts without native language equivalents

\begin{tabular}{llc}
\hline & \multicolumn{2}{c}{ \% Correct Interpretation } \\
Science Concept Tested & Test A & Test B \\
\hline Efficient & 18.1 & 37.0 \\
Contaminate & 30.2 & 32.9 \\
Effect & 16.6 & 25.8 \\
Essential & 40.0 & 40.8 \\
Rate & 20.3 & 28.1 \\
Source & 36.2 & 32.6 \\
Dehydrate & 19.4 & 24.2 \\
Proportion & 19.2 & 26.2 \\
System & 34.3 & 22.3 \\
Generate & 21.6 & 42.2 \\
Device & 34.8 & 22.3 \\
Crude & 22.4 & 39.1 \\
Independent & 58.0 & 27.7 \\
Constant & 19.9 & 21.3 \\
Average \% correct & 27.9 & 30.2
\end{tabular}

The students performed poorly on science words with native language equivalents in both tests (Tables 2). Less than 50\% gave correct interpretations to these words except for 'prepare' in test A where $51.9 \%$ of the students gave correct interpretations (Table 
2). Also the native equivalent for convert is "lere" but only $24.9 \%$ and $28.5 \%$ of he students gave correct interpretation to the word in test A and B respectively. Similarly, $26.5 \%$ and $24 \%$ of the students gave correct interpretation to the word "surround" with native equivalent "gelimi" in test A and B respectively. Perhaps there is no congruence between the science language meanings and those of their corresponding native equivalents. The meanings may be similar but not the same and the differences might have contributed significantly to the students' poor performance. The cultural experiences of the students with the native equivalent words might have influenced the meanings they gave to their corresponding science concept words.

Though the performance of the students on some of the science concept words without native equivalents (Table 3) was generally poor, their performance on some of these words in both tests (Tables $2 \& 3$ ) was better than their performance on some science words with native language equivalents (Table 2). The percentage scores of the students on some of the science concept words without native equivalents (Table 3 ) were higher than those of some of the science concept words in Table 2 with native equivalents. The students' performance on some of these words in both tests is given below:

Dehydrate: $\quad 19.4 \%$ in test $\mathrm{A}$ and $24.2 \%$ in test B

Contaminate: $30.2 \%$ in test $\mathrm{A}$ and $32.9 \%$ in test $\mathrm{B}$

Essential: $\quad 40 \%$ in test $\mathrm{A}$ and $40.8 \%$ in test B

Perhaps the better performance on such words may be due to the fact that the meanings of these words are not clouded by the cultural experiences of the students related to some of the native equivalent words. This seems to differ with some findings reported in the literature (Gay and Cole, 1967; Mori et. al., 1976; Yakubu, 1976; Tull, 1991) that non-equivalence between science concepts or science words in textbooks and native language of students can hinder the understanding of such words and hence affect their acquisition of science concepts. Therefore factors other than the presence or absence of native language of the learner, where instructions is in a foreign language, may affect the learner's understanding of science concept words. These factors include dissimilarity between the English meaning of the science word and its native language equivalent, and the interference of the cultural context meaning of the word. For example the equivalent word for estimate is 'mange' which means 'measure', for 'absorb' is 'ngu'. 'Ngu' has two English meanings depending on the context in which it is used and these are 'drink' and 'soak' (Table 2). The low score the students obtained in items involving estimate and absorb may be attributed to this lack of congruence between their English meanings and those of their corresponding native equivalents. For example most of the students interpreted estimates as 'careful measure' instead of 'careful guess' in both tests.

Fifty-eight percent of the students correctly interpreted 'independent' when used out of science context but this figure dropped to $28 \%$ (Table 3) when it was used in science context. The correct option for independent in test A was 'free'. The drastic drop in the students' correct responses to the word in test B may be attributed to their failure to get its contextual meaning. The commonest response among the students was ... 'as the baby

grows it needs more attention from the mother.' The students' responses seem to reflect their cultural experiences with growing babies. A toddler needs more attention as it gains mobility to prevent it from getting into trouble such as falling over an edge, etc. The students' experience as baby sitters to other siblings in the family might have influenced their interpretations of the word. This seems to confirm the findings 
(Mori, et. al., 1976; Tull, 1991) that where the learner fails to get the context of a word in science text she/he tends to interpret it from the perspective of his/her cultural environmental experience.

\section{Implications and Recommendations}

The poor performance of JSS students on science concept words in the tests may be due to poor standard of English language among basic school students. Similar studies (Sandman, 1993; Kraft, 1994) on the level of proficiency in English language of Ghanaian pupils at basic schools (Primary and JSS), reported that poor vocabulary and poor word association affected their proficiency in English language. A number of factors may account for this. The contact time of the students with English language is limited to the classroom. Very little English language is spoken at home since most adult Ghanaians are illiterate and this number is higher in the rural areas (World Bank Report, 1993).

Also there is a limited variety of English readers in the schools. In recent past teachers used to copy passages from readers on the chalkboard for the pupils to read. This affected the reading habits of the students with consequential effects on word vocabulary and comprehension of text. Despite the Government's effort to ensure that the ratio of English readers and textbooks on other subjects to students is one to one the ratio is still two to one and in some cases it is three to one.

Also oral spelling of words and written dictation of English words are no longer emphasised in the schools. This may lead to poor vocabulary which affect the meaning students give to science words encountered in science text and in everyday use of the English language. Science and language teachers should engage students in oral word spelling, dictation and word association exercises to improve the students' vocabulary. The word connections from these exercises will improve their comprehension of science words when encountered in science texts.

The ability to understand and explain in clear language the meanings of fundamental science concepts is central to science literacy. The inability to interpret correctly science concept words encountered in science textbooks and in every day use of the English language hinders students' understanding of science concepts and impedes science instruction.

Inadequate supply of recommended texts and other reading materials are common features in most developing countries where English is a second language. Therefore supply of adequate texts and other reading materials that could enhance students' conceptualisation of science words should be given the priority it deserves.

In countries where the medium of instruction for the first three years of schooling is in the local language, the headteachers should enforce the use of English language as medium of communication within the school premises to increase the contact time of students with the language.

Studies by Mori et al (1976) and Yakubu (1976) reported that where native equivalents to science words exist the students are able to understand the latter. This was not so in this study. Their studies were conducted in elementary schools where the native language was the official language of communication for the greater part of the programme. Though the native language is officially recommended for the first three years of elementary school instruction in most cases, it is used for the greater part of the elementary school because of the poor acquisition of English words by the pupils. They are therefore amenable to native words than English ones. Hence their 
better performance in some science words with native language equivalents is not unexpected.

At the JSS level the recommended medium of instruction is English language, perhaps this practice is responsible for the JSS better performance in science words without native language equivalents. Also some of these words are encountered frequently by students in everyday use of English language and in science text. For example, the word "essential" in essential commodities", is household terms in Ghana and for 'independent', Ghanaian students in basic schools celebrate Independence Day annually.

The poor performance on science words with native equivalents could be attributed to the early switch from the native language of the students to English language as medium of instruction in Ghanaian schools. The switch is effected after the first three years of basic school education. Collison (1974) compared the native language(s) (of Ghanaian pupils) and English language to find out which of these was a better medium of instruction. The native languages were better media for instruction of pupils at the basic level. He recommended a long period of instruction of pupils in their native languages at the basic school for better conceptual development because high linguistic and cognitive development in the child can lead to transfer of linguistic skills to a second language (Kraft, 1994).

The findings of this study suggest the use of the native language along side English language in science instruction for proper language development and effective transfer to the second language after the elementary. Also when students begin to use the second language exclusively for learning then the native language should be discontinued for any reason whatsoever to avoid confusion.

Ghana, like other countries where English language is studied as a second language, the true position is that English might really be the third or fourth language. In most cases it is the language of the majority tribe that becomes the official local language in schools (Ghana, Nigeria, Sierra Leone among other countries). For example in this study the major native languages spoken are Nankani, Buli and Kassem but Kassem is the official language used in schools. It means that those who speak Nankani and Buli have first to learn Kassem as second language and English as a third language. The impact of this practice on students' performance in science needs to be investigated.

\section{References}

Alexander, H.G. (1976). Language and Thinking. D. Van, Nostrand Company

Bently, D. and Watts, M. (1992) Communicating in School Science, London. Palmer Press,

Benz, C. (1996). 'Entering an Academic discourse community: A case study of the coping strategies of Eleven English as L2 students', Dissertation Abstracts International, 57, 8, 3365 - 3367.

Collison, G.O. (1974). Concept formation in a second language: A study of Ghanaian School Children. Harvard Educational Review, 44, 3. 441-157.

Garcia, E.E., Ku, Y-M. and Reyes, (2001). Science for all: Promoting science and literacy for linguistically and culturally diverse elementary students. An Ethnographic Study. Dissertation Abstract. International. 51, 11, 36923693 . 
Gay, J. and Cole, M. (1967) Cited by Ogbu, J.U. (1992) Understanding Cultural Diversity and Learning. Educational Researcher, 21, 8, 5-14.

Kraft, R. J. (1994) Teaching and learning in Ghana: a curriculum, textbook, syllabus and handbook analysis. Accra, Ghana: Ministry of Education.

Mori, L. and Kitagawa, O. (1974): The effect of language on a child's conception of speed: A comparative study on Japanese and Thai Children. Science Education, 60, 4, 531-534.

Mori, L. et. al. (1976): The effect of language on a child's conception of speed: A comparative study on Japanese and Thai Children. Science Education, 60, 4, 531-534.

Sandman, R.S. (1993). The Criterion-Referenced Test for Primary Six: Results of Pilot Testing Accra: USAID and Ministry of Education.

Tobin, K. and Mcrobbie, C.J. (1996). Significance of limited English Proficiency and Cultural capital to the performance in Science of Chinese - Australians. Journal of Research in Science Teaching, 33, 3, 265-282.

Tull, D.I. (1991) Elementary Science: Students concepts in Biology: Their Language, Meaning, Classification and Interpretations of Science Concepts:

World Bank Development Report (1993). Education in Sub-Saharan Africa: Policies for adjustment, revitalisation and expansion, Baltimore, John Hopkins University Press.

Yakubu, J.M. (1976) Influence of Culture on Learning and Teaching of Science in Northern Ghana, Science Teacher, 20, 1 and 2, 60-75. 